\section{Gas-liquid chromatography in diagnosis of pyogenic arthritis}

Pyogenic arthritis must be diagnosed early if joint destruction is to be avoided. Differentiation from other arthropathies is crucial, and immediate aspiration and culture of synovial fluid is essential when infection is suspected. Synovial fluid contains pus cells in all inflammatory arthropathies and, since Gram-staining is of limited reliability, a further rapid screening test for infection would be of great help. The end products of in-vivo bacterial metabolism can be detected in clinical samples by gas-liquid chromatography (GLC). ${ }^{1}$ This technique has been applied to joint fluids in Reiter's disease and gonococcal arthritis. ${ }^{2}$ The published methods are complex, entailing extraction and derivatisation of the metabolic products in the sample. We decided to evaluate a simplified, rapid technique, avoiding both extraction and derivatisation, for identifying volatile fatty acids in joint fluid.

\section{Patients, methods, and results}

Patients were included in the study if they had appreciable joint effusion. All were examined clinically, radiologically, and by laboratory investigation Of the 73 patients included, 20 had Reiter's disease, seven benign gonococcal arthritis (Neisseria gonorrhoeae not being isolated from the joint fluid itself) five had infected joints (three with Staphylococcus aureus, one $\mathrm{N}$ gonorrhoeae, one non-haemolytic streptococcus), 10 seronegative rheumatoid arthritis, five seropositive rheumatoid arthritis, six degenerative arthrosis, and two crystal synovitis. Eighteen patients had an assortment of arthropathies, mostly unclassified, but including psoriatic and colitic arthropathy.

Joint fluids were collected aseptically without local anaesthesia, which might have interfered with GLC. Specimens were divided into two aliquots and either examined immediately or stored at $-20^{\circ} \mathrm{C}$ with or without citrate as an anticoagulant. The joint fluids were injected, without extraction or derivatisation, into a Pye-Unicam series 104 chromatograph operating isothermally at $200^{\circ} \mathrm{C}$ with columns $1.5 \mathrm{~m}$ long and $4 \mathrm{~mm}$ bore packed with Chromosorb 101. Results were displayed graphically with a Philips PM8220 pen recorder. This technique allows the detection of a wide range of volatile organic fatty acids including acetic acid in concentrations above $1 \mathrm{mmol} / \mathrm{l}$ $(5.9 \mathrm{mg} / 100 \mathrm{ml})$ and lactic acid above $10 \mathrm{mmol} / 1(90 \mathrm{mg} / 100 \mathrm{ml})$. Three specimens of joint fluid from patients with degenerative arthrosis were inoculated, one each with Staph aureus, Streptococcus pyogenes, and $N$ gonorrhoeae, and then analysed after overnight incubation.

All samples produced traces, the first three minutes of which could be

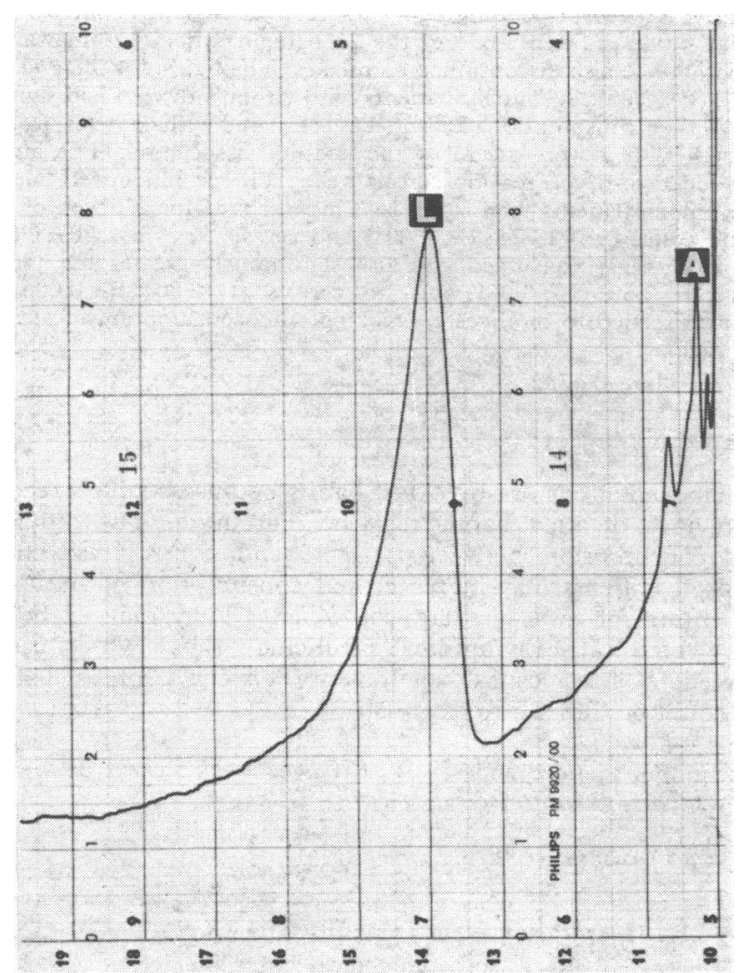

Chromatograph showing, from right to left, acetic acid peak $A$ and high lactic acid peak $L$ associated with joint infections. reproduced with serum and whole blood, with an acetic acid peak at six minutes (figure). The five culture-positive fluids also produced very high lactic acid peaks (c $50 \mathrm{mmol} / 1$ (c $450 \mathrm{mg} / 100 \mathrm{ml}$ )) (figure). Two patients with a clinical diagnosis of gonococcal arthritis but with negative joint-fluid cultures produced lactic acid peaks, but these were not found in fluids inoculated with bacteria or samples containing many pus cells but no bacteria.

\section{Comment}

With this simple technique of GLC examination we detected high lactic acid concentrations in all culture-positive joint fluids and in two patients with gonococcal arthritis but culture-negative joint fluid. Lactic acid was not detected in other equally purulent joint fluids, or fluids where organisms were introduced in vitro. These findings are largely supported by the brief report of Reza et al. ${ }^{3}$ Detection of lactic acid therefore seems to be a useful screening test for the presence of infection. Even simpler techniques could make this a bedside procedure.

MHS is grateful to the Arthritis and Rheumatism Council for support for this study.

${ }^{1}$ Mitruka, B M, Gas Chromographic Applications in Microbiology and Medicine. New York, John Wiley, 1975.

${ }^{2}$ Brooks, J B, et al, fournal of Infectious Diseases, 1974, 129, 660.

${ }^{3}$ Reza, M J, et al, in a Communication to the XIV International Congress of Rheumatology, 1977, Los Angeles.

(Accepted 13 September 1978)

Departments of Rheumatology and Microbiology, St Thomas's Hospital, London SE1 7EH

M H SEIFERT, MB, MRCP, consultant physician (present address: St Mary's Hospital, London W2 1NY)

J A MATHEWS, MB, MRCP, consultant physician

I PHILLIPS, MRCP, MRCPATH, professor of microbiology

R A GARGAN, FIMLs, medical laboratory scientific officer (present address: Royal Free Hospital, London NW3)

\section{Myasthenia gravis and red cell aplasia}

Myasthenia gravis and pure red cell aplasia (PRCA) are two rare diseases that are often associated with thymic tumours. This repor describes a patient with myasthenia in whom red cell aplasia responded dramatically to corticosteroid therapy.

\section{Case report}

A 51-year-old blacksmith presented in January 1972 with a month's history of double vision, ptosis, and difficulty in prolonged talking. These features were dramatically relieved by intravenous edrophonium, confirming the diagnosis of myasthenia gravis, and subsequently his condition was well controlled by neostigmine and pyridostigmine. He remained well for the nex six years, apart from long-standing chronic obstructive airways disease. In November 1977 he was admitted as an emergency with congestive cardiac failure secondary to severe anaemia. Investigation showed haemoglobin $3.7 \mathrm{~g} / \mathrm{dl}$; leucocytes $7.3 \times 10^{9} / 1\left(7300 / \mathrm{mm}^{3}\right)$ (neutrophils $4.8 \times 10^{9} / 1(4800$ $\left.\mathrm{mm}^{3}\right)$ ); platelets $56 \times 10^{9} / 1\left(56000 / \mathrm{mm}^{3}\right)$; ESR $175 \mathrm{~mm}$ in $1 \mathrm{~h}$; reticulocytes $0.0 \%$; direct antiglobulin test positive (cells IgG coated); serum IgG $2700 \mathrm{mg} / 100 \mathrm{ml}$; serum IgA $540 \mathrm{mg} / 100 \mathrm{ml}$; serum IgM $220 \mathrm{mg} / 100 \mathrm{ml}$ antibodies to striated muscle were detected. Bone marrow aspiration produced hypocellular fragments with a decrease in granulopoietic and megakaryocyte elements, but was most notable for the complete absence of red cell precursors. Chest $x$-ray examination and tomography showed no evidence of thymoma. An EMI scan of the thorax later showed a nodule $0.5 \mathrm{~cm}$ in cross section and $3 \mathrm{~cm}$ long in the anterior mediastinum, which could have been in the thymus but equally well could have been a lymph node.

Red cell aplasia was diagnosed and the patient was treated with diuretics and transfusion of six units of red cells. Corticosteroid therapy was started initially with hydrocortisone $200 \mathrm{mg}$ six-hourly and subsequently with prednisolone $40 \mathrm{mg}$ daily. After the transfusion the haemoglobin concentration continued to rise and eight months later was stable at $13.8 \mathrm{~g} / \mathrm{dl}$; leucocytes $10.7 \times 10^{9} / 1\left(10700 / \mathrm{mm}^{3}\right)$; platelets $282 \times 10^{9} / 1\left(282000 / \mathrm{mm}^{3}\right)$. The dosag 
of prednisolone was reduced to $5 \mathrm{mg}$ daily without relapse. The direct antiglobulin test became negative three months after he started treatment. $\mathrm{He}$ has remained well and control of his myasthenia has been unaffected. Thymectomy has not been recommended because of his poor respiratory reserve.

\section{Comment}

The relation between myasthenia gravis and thymoma or microscopic hyperplasia of the thymus is well known. ${ }^{1}$ The syndrome of PRCA and thymoma is also well established. Roland ${ }^{2}$ reviewed 43 cases of the latter and reported the incidence of thymoma in PRCA in adults as $57 \%$. Six of these patients had associated myasthenia gravis and about one-third also had depression of the myeloid or megakaryocyte series, or both. In three patients the thymomas were too small to be shown by radiography and were unsuspected findings at necropsy. Thirty-two of the 43 patients received specific therapy, including thymectomy, thymic irradiation, corticosteroids, androgens, and splenectomy in various combinations: but only one patient had a remission on corticosteroid treatment alone.

There is now much evidence pointing to an autoimmune basis to PRCA $^{3}$ and immunosuppressive drugs may be used in treatment, often with satisfactory results. A humoral inhibitor may be secreted by a thymoma, but a disruption of immunological homeostasis, possibly mediated by a loss of controlling function of $\mathbf{T}$ lymphocytes, seems more likely. ${ }^{4}$ IgG serum inhibitors have been demonstrated against erythroid marrow and also against circulating erythropoietin. ${ }^{5}$ These inhibitors have always disappeared with remission after thymectomy or immunosuppressive treatment. Our patient was unusual in that his peripheral red cells were coated with IgG. But the most remarkable feature of the case was the prompt and gratifying response to corticosteroids alone. This is rare among a series of reports of patients requiring multiple transfusions, major surgery, and immunosuppressive drugs to try to achieve remission.

${ }^{1}$ Castleman, B, and Norris, E A, Medicine, 1949, 28, 27.

2 Roland, A S, American fournal of the Medical Sciences, 1964, 247, 719.

${ }^{3}$ Krantz, S B, British fournal of Haematology, 1973, 25, 1.

4 Allison, A C, Derman, A M, and Barnes, R D, Lancet, 1971, 2, 135.

${ }^{5}$ Marmont, A, et al, Blood, 1975, 45, 247.

(Accepted 12 September 1978)

\section{General Hospital, Nottingham NG1 6HA}

J B HOUGHTON, MB, MRCP, senior registrar in haematology

P J TOGHILL, MD, FRCP, consultant physician pain or hypertension or raised serum urea or urate concentrations. A history of known lead exposure was a ground for exclusion in both groups. Serum lead excretion. ${ }^{5}$ Some unknown factor may reduce the excretion of

B C CAMPBELL, MD, MRCP, lecturer may be higher in lead nephropathy than in comparable degrees of renal failure from other causes, ${ }^{2}$ and an increase in nuclear-protein turnover may contribute to this. ${ }^{3}$ While a history of frank lead poisoning is uncommon in patients presenting with gout in the UK, a study of the effects of chronic low-grade lead exposure from drinking water showed hyperuricaemia to be significantly associated with raised blood lead concentrations in a symptom-free population. We have studied the blood lead concentrations in patients with gout who gave no history of overt lead exposure.

\section{Patients, methods, and results}

We studied 32 patients suffering from gout. Their ages ranged from 18 to 70 years (mean 45.5 years), and all except a 68 -year-old woman were men. All had clearly documented gouty arthritis, having been found to have hyperuricaemia and urate crystals in articular aspirate. Most of the patients had normal serum urea $(5.51 \pm$ (SE of mean) $0.2 \mathrm{mmol} / 1(33.2 \pm 1.2 \mathrm{mg} / 100$ $\mathrm{ml})$ ) and creatinine $(89.7 \pm 2.3 \mu \mathrm{mol} / 1(1.0 \pm 0.03 \mathrm{mg} / 100 \mathrm{ml}))$ concentrations, but serum urea was raised in five patients and serum creatinine in three. We also studied 32 age- and sex-matched controls. None had a history of joint urate was estimated by a standard automated technique and the blood lead concentration by atomic absorption spectrophotometry using a Perkin Elmer 306 flameless atomic absorption spectrophotometer with HGA 72 graphite-cell power source.

As a group the patients with gout had higher blood lead values than the controls (see table). For example, none of the gouty subjects had a blood lead concentration of under $0.4 \mu \mathrm{mol} / 1(8.3 \mu \mathrm{g} / 100 \mathrm{ml})$, and, whereas only four controls had blood lead concentrations of over $1.5 \mu \mathrm{mol} / 1(31 \mu \mathrm{g} / 100 \mathrm{ml})$ 16 of the patients exceeded this concentration. In only three of the 32 pairs did the control have a blood lead concentration in a higher range than the patient. Reference to the binomial distribution yielded a highly significant result $(P<0.001)$

Blood lead concentrations in 32 patients with primary gout and 32 age- and sex-matched controls

\begin{tabular}{l|c|c|c|c|c|c|c|c}
\hline Blood lead $(\mu \mathrm{mol} / \mathrm{l}):$ & $<0.4$ & -0.8 & -1.2 & -1.6 & -2.0 & -2.4 & -2.8 & -3.2 \\
\hline $\begin{array}{l}\text { No of patients } \\
\text { No of controls }\end{array}$ & 5 & 2 & 13 & 6 & 5 & 4 & 1 & 1 \\
\hline
\end{tabular}

Conversion: SI to traditional units-Lead: $1 \mu \mathrm{mol} / 1 \approx 20 \cdot 7 \mu \mathrm{g} / 100 \mathrm{ml}$.

\section{Discussion}

These findings leave no doubt that raised blood lead values and gout are associated, though they do not prove that lead helped to cause the gout in these patients. Gout nephropathy may have caused diminished renal lead excretion with a resulting increase in blood lead concentrations, but this group of patients mostly had normal renal function. Moreover, even severe renal failure may not depress renal both lead and urate. This, however, seems unlikely since urate is excreted by the renal tubules, whereas lead seems to be excreted mainly by glomerular filtration.

Thus our findings, taken with the association between lead and symptomless hyperuricaemia found previously, ${ }^{4}$ suggest that lead is sometimes a causal factor in gout. Gout may be another manifestation of subclinical lead poisoning.

1 Campbell, B C, and Baird, A W, British fournal of Industrial Medicine, $1977,34,298$.

${ }^{2}$ Emmerson, B T, Australasian Annals of Medicine, 1963, 12, 310.

${ }^{3}$ Ludwig, G D, Archives of Internal Medicine, 1957, 100, 802

4 Campbell, B C, et al, British Medical fournal, 1977, 1, 482.

${ }^{5}$ Campbell, B C, and Elliott, H L, British Medical fournal, 1977, 2, 581.

(Accepted 15 September 1978)

University Department of Materia Medica, Stobhill General

Hospital, Glasgow G21 3UW

M R MOORE, BSC, PHD, lecturer

A GOLDBERG, MD, FRCP, regius professor of materia medica (now regius professor of medicine, University Department of Medicine, Western Infirmary, Glasgow G12 8QQ)

Centre for Rheumatic Diseases, Glasgow

L A HERNANDEZ, MD, research assistant

W CARSON DICK, MD, consultant physician

\section{Oral choline in cerebellar ataxia}

There is no established drug treatment for cerebellar ataxia. Cerebellar physiology is well established but its synaptic chemistry is only partly understood. In particular, the nature of the excitatory synapses is uncertain and whether specific defects in synaptic transmission underlie cerebellar movement disorders is unknown. Anticholinesterases produce small improvements in cerebellar ataxia after a single dose but are of no long-term clinical use. ${ }^{1}$ This preliminary report describes a patient whose ataxia was greatly improved by oral choline, another means of enhancing cholinergic neurotransmission. 